\title{
História Hoje: primeiros números ou um (re)começo
}

\section{História Hoje Journal: first numbers or a (re)beginning}

Cláudia Sapag Ricci*

\section{RESUMO}

O texto apresenta a análise dos três primeiros números da Revista História Hoje, publicados em 2012 e 2013, após uma reformulação editorial que visou revitalizá-la intensificando o seu papel de diálogo entre reflexões do campo historiográfico e os desafios do ensino de História na Educação Básica. Situa o período de transição com as publicações anteriores a partir do registro das reuniões da diretoria da Anpuh nacional no período de 2009 a 2013. Apresenta um mapeamento das temáticas abordadas e do perfil dos/ as autores/as (gênero, área de conhecimento, nível de ensino, vinculação profissional) dos referidos números.

Palavras-chave: Revista História Hoje; reformulação editorial; autoria.

\begin{abstract}
The text presents an analysis of the first three issues of the História Hoje Journal, published in 2012 and 2013, after an editorial reformulation that aimed to revitalize it, intensifying its role as a dialogue between reflections in the historiographic field and the challenges of teaching History in basic education. It locates the transition period with previous publications from the record of the national Anpuh board meetings in the period 2009 to 2013. It presents a mapping of the themes addressed and the profile of the authors (gender, area of knowledge, level of education, professional link) of the referred numbers.

Keywords: História Hoje Journal; editorial overhaul; authorship.
\end{abstract}

Costumo sempre dizer que quem me ensinou a ler foi Déa Fenelon, quando professora da disciplina Núcleo de Pesquisa, no curso de mestrado da Pontifícia Universidade Católica de São Paulo (PUC-SP), no início da década de 90 do século passado. Nas aulas, após a organização dos grupos e respectivas temáticas relativas ao projeto de pesquisa de cada estudante, Déa fazia a indicação de bibliografia e a seguinte orientação: inicialmente, ao realizar a leitura

\footnotetext{
* Universidade Federal de Minas Gerais (UFMG), Belo Horizonte, MG, Brasil. ricci.clau@gmail.com
} 
indicada, é fundamental, antes mesmo de conhecer o conteúdo, buscar situar quem é/são os/as autores/as - trajetórias de pesquisa e estudo, vinculação institucional, atuação profissional; o referencial teórico utilizado e o contexto da elaboração do texto.

De certa forma, esse caminho tem sido trilhado ao ler e analisar artigos e textos, de uma forma geral. Tal perspectiva não foi muito diferente da sugestão feita ao grupo de autores/as pela coordenadora, professora Margarida Dias, ao nos convidar para essa imersão sobre a Revista História Hoje, publicação da Associação Nacional de História (Anpuh). A mim coube o desafio de análise dos números publicados em 2012 e 2013, considerados os três primeiros após a reformulação de sua linha editorial.

Com um roteiro bastante flexível e em diálogo com os/as autores/as responsáveis pela análise dos demais números da revista, procuramos, além de refletir sobre a estrutura e as temáticas abordadas, situar os/as autores/as, o contexto sociopolítico, especialmente relativo ao campo educacional e às políticas da Anpuh em relação ao ensino de História. Ou seja, uma análise que busca contextualizar a produção em foco.

Uma das sugestões da coordenação foi a realização de entrevistas de acordo com as análises realizadas. Inicialmente, a opção para este texto foi dialogar com a editora dos três números em análise e com coordenadores/as dos dossiês. Nesse sentido, foi feito o convite, via e-mail, para Patrícia Maria Melo Sampaio (UFAM); Martha Campos Abreu (UFF) e Silvio de Almeida Carvalho Filho (UFRJ); Circe Bittencourt (PUC-SP) e Maria Aparecida Bergamaschi (UFRS); Helenice Rocha (UERJ) e Wilma Baía Coelho (UFPA). E, para tentar situar o significado dos números em análise serem denominados "primeiros números", foram feitos convites para entrevistas também para a professora Juçara Luzia Leite (UFES) e para o professor Luís Fernando Cerri (UEPG), editora da Revista História Hoje e $2^{\circ}$ secretário, da gestão 2009-2011, respectivamente. $^{1}$

Além das entrevistas, um mergulho na documentação da Anpuh, especialmente nas atas das reuniões da diretoria nacional realizadas no período de 2009 a 2013, foi fundamental para a contextualização dos números da Revista História Hoje em análise. ${ }^{2}$ 


\section{NOVOS RUMOS}

A ideia "os primeiros" sempre provoca uma certa curiosidade sobre esse “início", essa "origem” ou "gênese”. Sabemos, especialmente nós historiadores/ as, que os chamados inícios têm sempre uma história que os precede.

Ao pesquisar o site da Anpuh, na aba REVISTAS ANPUH, no item REVISTA HISTÓRIA HOJE - APRESENTAÇÃO, há informações sobre a publicação de seu primeiro número em julho de 2003, com o objetivo de "divulgar a produção historiográfica recente, temas da atualidade e experiências didáticas em todos os níveis" e a definição de alterações em sua linha editorial após a publicação de 14 números, ao longo de oito anos com a publicação de um dossiê, em 2012, inaugurando essa nova série.

Em julho de 2011, um novo Conselho Editorial, com o apoio da ANPUH, revitalizou a revista por meio de mudanças importantes. Redefiniu a estrutura de sua linha editorial que a partir de então passou a privilegiar as interfaces que relacionam História e Ensino. Também criou novas seções - História Hoje na Sala de Aula, E-Storia e Falando de História Hoje - e passou a investir na publicação de Dossiês Temáticos. A revista teve sua periodicidade ajustada, passou a ser semestral e assumiu o formato eletrônico migrando para a base OJS/SEER. Em junho de 2012, inaugurou uma nova série com a publicação do Dossiê Ensino de História da África e da Cultura Afro-brasileira. A partir de 2013 a revista passou a adotar a seleção de propostas de dossiês temáticos, por meio de editais divulgados em diferentes meios entre os especialistas da área. (APRESENTAÇÃO, s. d., s. p., grifos nossos)

Ainda no site da Anpuh, na aba QUEM SOMOS, item DIRETORIA NACIONAL, há certa descontinuidade na indicação da editoria da Revista História Hoje: consta o nome do professor José Miguel Arias Neto (UEL) como editor na gestão 2003-2005, presidência de Luís Carlos Soares (UFF); do professor Gilvan Ventura (UFES) na gestão 2005-2007, presidência de Eni de Mesquita Samara (USP); nenhuma referência na gestão 2007-2009, presidência de Manoel Luiz Salgado Guimarães (UFRJ); como editora a professora Juçara Luzia Leite (UFES) na gestão 2009-2011, presidência de Durval Muniz de Albuquerque Júnior (UFRN) e, na gestão 2011-2013, consta o nome da 
professora Patrícia Maria Melo Sampaio (UFAM) como editora e presidência de Benito Bisso Schmidt (UFRGS).

Uma consulta às atas de reuniões da diretoria da entidade revela a preocupação, desde anos anteriores, com a linha editorial da Revista História Hoje, especialmente no tocante a sua diferenciação com a outra publicação da entidade, a Revista Brasileira de História, como é perceptível no trecho da Ata da Reunião da Diretoria da Anpuh Nacional, ocorrida dia 24 de agosto de 2009:

Durval inicia a discussão sobre a Revista História Hoje. Questiona a diretoria sobre a manutenção ou não da revista. Diz que só faz sentido mantê-la se seguir uma linha editorial totalmente distinta da RBH. Ficou decidido que as atividades ficarão suspensas para reestruturação e definição de missão editorial. Cerri propôs contato com a Associação Brasileira de Ensino de História, para pensarem na revista. Todos concordaram. (ANPUH, 2009)

Em reunião da diretoria nacional da Anpuh, realizada em 31 de outubro de 2009, é reiterada a suspensão da publicação da Revista História Hoje, sendo ressaltado que docentes da Educação Básica deveriam ser seu público leitor, conforme registro em ata:

O presidente informou que a Revista História Hoje está momentaneamente suspensa, mas que será retomada assim que sua missão for definida com critério. A ideia inicial é que seja voltada ao professor, com material didático, documentos de apoio, etc. O editor ainda não foi escolhido. (ANPUH, 2009)

Os rumos da Revista História Hoje são questões recorrentes e ponto de pauta em mais uma reunião da diretoria nacional, realizada em 11 de dezembro de 2009. São várias as sugestões apresentadas visando a revitalização da revista, segundo a ata de tal reunião: aproximação com a Associação Brasileira de Ensino de História e com o Grupo de Trabalho de Ensino de História; indicação de Sonia Miranda e Juçara Luzia Leite para editoria; sugestão para que Luís Cerri seja o editor chefe com dois editores executivos; periodicidade semestral; que os autores sejam professores que atuem no ensino de História independentemente de sua titulação. Como encaminhamento, o professor Cerri comprometeu-se a refazer os termos da Revista História Hoje e compar- 
tilhar com todos para complementações e revisões que ainda fossem consideradas necessárias.

Em entrevista realizada, o professor Cerri (2001) lembra que ao longo de sua gestão na $2^{\text {a }}$ secretaria da Anpuh nacional, discussões e reflexões sobre a Revista História Hoje foram realizadas. Citou, especialmente, a reunião de 23 de abril de 2010, quando uma outra proposta da linha editorial foi apresentada e alvo de debate. As imagens a seguir são trechos do documento "Convocação de Reunião com as Seções Regionais”, disponibilizado pelo professor Cerri:

\section{Figura 1 - Documento Convocação de Reunião}

com as Seções Regionais, Anpuh - 2010.

\section{Convocação de Reuriaño com as Seçōes Regionais}

Convocamos todas as Seções Regionais da ANPUH a enviarem representantes para uma reuniâo que ocorrerá no dia 23 de abril a partir das 09:00 da manhã na sede da ANPUH Nacional, campus da USP, com a șèguinte pauta:

Y-Informes:

2) Aprovação da Ata de Reuniâo Anterior

3 - Formato do XXVI Simpósiơ Nacional de História

4-Campanha Nacional de Filiaçẩo

5 Finanças da Entidade, Reorganização Administrativa e Regulamentação dos Núcleos

V- Atividades de Comemoração dos 50 anos da Entidade

7- Regulamentação da Profissão - PL 7321-Câmanco

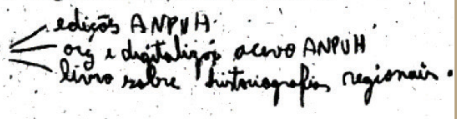

8-Fórum de Pós-Graduaçăo e Prềmio Teses - UNiRio

9- Formato dos Fóruns de Graduação

10 - Revista Brasileira de História

11 - Revista História Hoje

12 - Relacionamento Regionais e Nacional

Fonte: Cedido por Luis Fernando Cerri. 
Figura 2 - Documento Convocação de Reunião com as Seções Regionais, Anpuh - 2010. Trecho referente à Revista História Hoje.

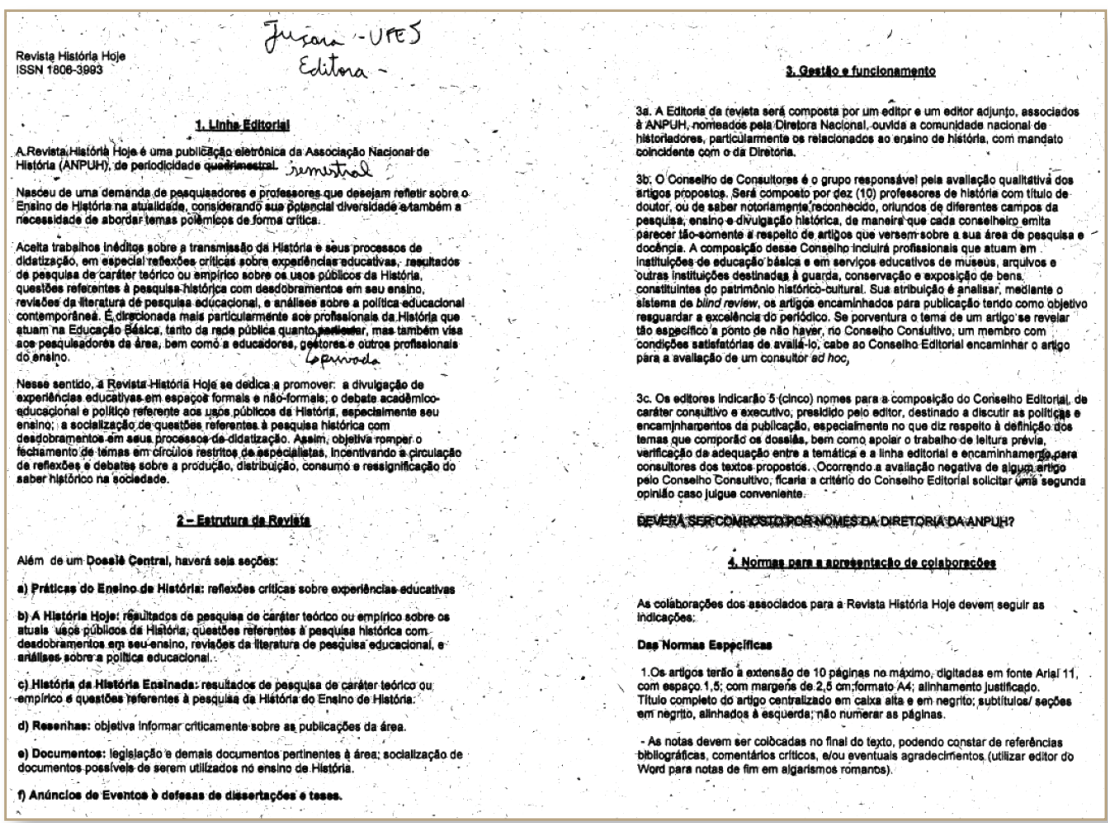

Fonte: Cedido por Luis Fernando Cerri.

$\mathrm{Na}$ ata da referida reunião, é perceptível a tentativa de consolidar uma publicação voltada para o ensino de História, diferenciando-se, nesse sentido, da Revista Brasileira de História e apostando em sua "valorização":

Passam para a proposta editorial da Revista História Hoje. A periodicidade seria semestral. É lida a proposta enviada pela editora Juçara Luzia Leite, anexada ao final desta Ata. Este periódico, para não ser uma outra versão da RBH se voltaria unicamente ao Ensino de História. Como uma das propostas da RHH é disponibilizar materiais didáticos on-line pede-se aos presentes que nos informem sobre laboratórios dentre outras fontes que poderemos utilizar. Sua periodicidade será de abril e setembro, intercalando com a RBH. Pede-se que os núcleos auxiliem as produções enviando-nos experiências de ensino ou novas demandas que possam ter deste periódico. O ideal é que seja uma Revista bastante versátil e que 
promova uma navegação ampla ao seu leitor. Nelson Schapochnik acrescenta que essa inovação da RHH é justamente para que ela perca a alcunha de um periódico inferior e que seja dotada de uma utilidade diversa, mais prática e objetiva, apresentando ao leitor um resultado completamente diferente do até então realizado. (ANPUH, 2010)

As discussões sobre a chamada "revitalização" da Revista História Hoje continuam ocupando lugar nas reuniões ao longo de 2010 e mesmo no primeiro semestre de 2011. Em entrevista realizada com a professora Juçara Luzia Leite, editora da Revista História Hoje na gestão 2009-2011, a presidência da Anpuh, através de um e-mail datado de 4 de junho de 2011, solicitou ao responsável pelo site a retirada do número da Revista História Hoje então publicado. A justificativa dada foi que o material disponibilizado se encontrava sem tratamento gráfico (sem capa, por exemplo) e que era necessário ser mais interativa.

A professora Juçara ressaltou as dificuldades de infraestrutura enfrentadas naquele momento, "sem estagiário ou qualquer suporte para concretizar a proposta da Revista História Hoje ser um instrumento de diálogo entre 'a voz do professor' e pesquisas no campo do ensino de História" (LEITE, 2021). Tais dificuldades, ao que parece, perduraram, pois há registro na ata de reunião de 15 de abril de 2011, sobre "as dificuldades que a revista passa por não ter uma secretaria" (ANPUH, 2011).

\section{OS “NOVOS” E OS “ANTERIORES"}

É possível acessar todos os números publicados da Revista História Hoje no site da Anpuh, na aba REVISTAS ANPUH, no item REVISTA HISTÓRIA HOJE. Há dois links denominados VOLUMES NOVOS e VOLUMES ANTERIORES, revelando a delimitação entre o "antes" e o "depois" da reformulação da linha editorial da publicação: 
Figura 3 - Revista História Hoje no site da Anpuh.

\section{REVISTA HISTÓRIA HOJE}

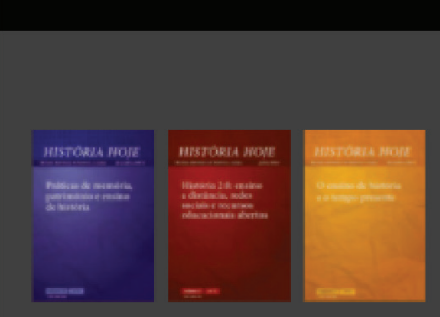

\section{VOLUMES NOVOS | VOLUMES ANTERIORES}

Fonte: Anpuh. Disponível em: https://anpuh.org.br/index.php/revistas-anpuh/revista-historia-hoje-i. Acesso em: 04 mai. 2021.

Figura 4 - Revista História Hoje no site da Anpuh, Volumes anteriores.

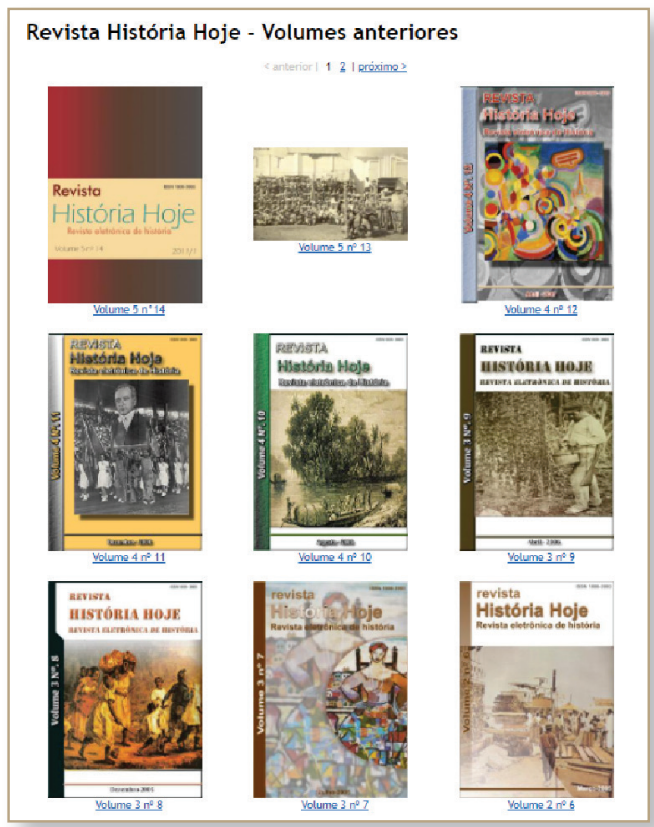

Fonte: Anpuh. Disponível em: https://anpuh.org.br/ index.php/revistas-anpuh/revista-historia-hoje-i/ numeros-anteriores. Acesso em: 04 mai. 2021. 
Figura 5 - Revista História Hoje no site da Anpuh, Volumes novos.

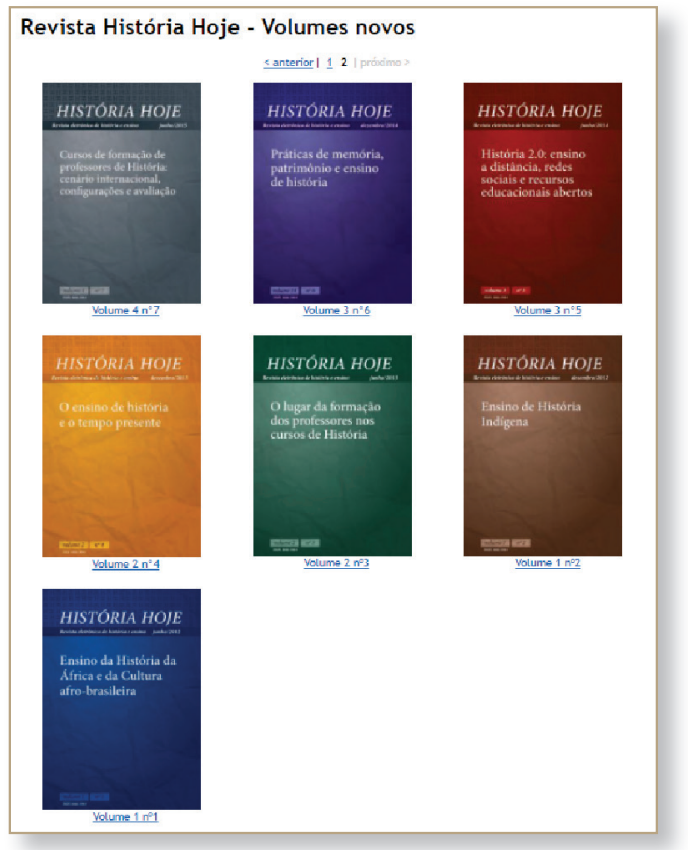

Fonte: Anpuh. Disponível em: https://anpuh.org.br/ index.php/revistas-anpuh/revista-historia-hoje-i. Acesso em: 04 mai. 2021.

A penúltima publicação apresentada no conjunto denominado VOLUMES ANTERIORES é o número 13, referente ao segundo trimestre de 2007. Tal publicação é composta pelos seguintes itens: Expediente, Apresentação, seis artigos e três resenhas. Já no último, volume 5, número 14, constam links para somente sete artigos. Não há os itens "Expediente" e "Apresentação". Somente na imagem que pode ser considerada uma capa há a indicação do período: 2011/1. 
Figura 6 - Revista História Hoje no site da Anpuh. Volume 5, número 14.

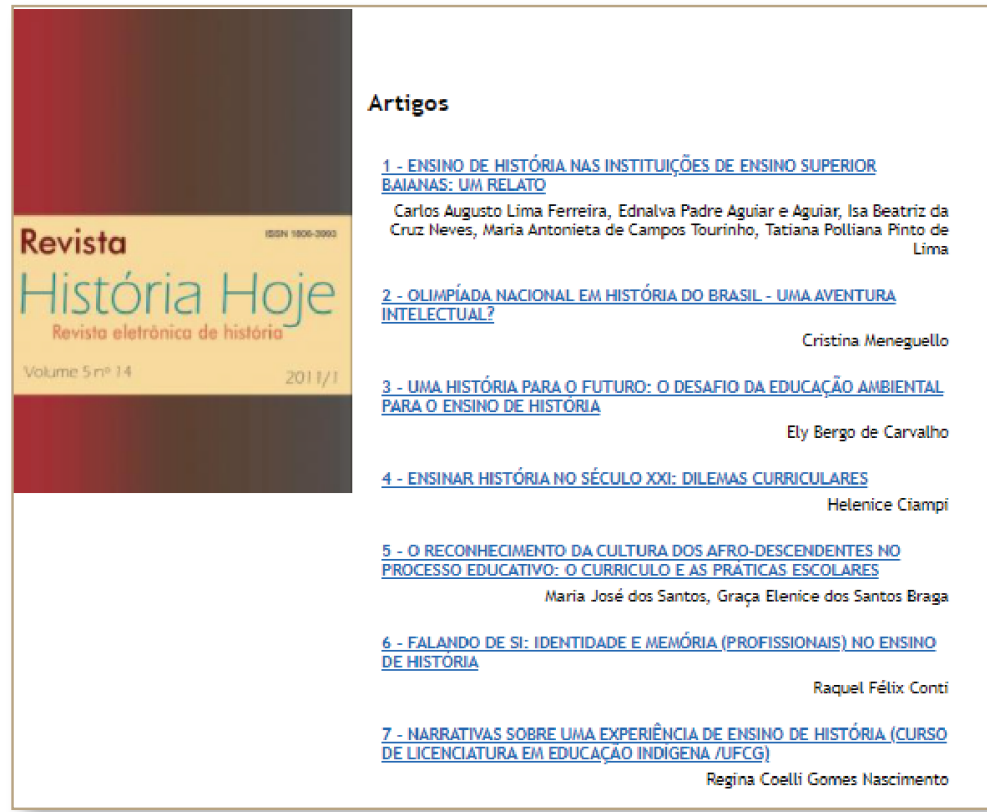

Fonte: Anpuh. Disponível em: https://anpuh.org.br/index.php/revistas-anpuh/ revista-historia-hoje-i/numeros-anteriores. Acesso em: 04 mai. 2021.

O contraponto com a estrutura dos denominados "volumes anteriores" é bastante clara. Os três números da Revista História Hoje em análise, publicados em 2012 e 2013, sob a editoria da professora Patrícia Maria Melo Sampaio (UFAM), têm como eixo um dossiê temático, acompanhado das seguintes seções: Entrevista; Falando de História Hoje; E-Storia; História Hoje na Sala de Aula; Resenhas e Artigos, detalhados a seguir.

\section{SOB NOVA DIREÇÃO: TEMÁTICAS, ABORDAGENS E CONTEXTO SOCIOPOLÍTICO}

Os dossiês de cada um dos números em análise têm como tema "Ensino de História da África e da Cultura Afro-brasileira”, "Ensino de História Indígena" e "O lugar da formação do professor nos cursos de História”, revelando uma clara relação com questões em pauta no âmbito da legislação educacional, 
objeto de estudos, pesquisas e debates, como as leis no 10.639/2003, nº 11.645/2008 e as Diretrizes Curriculares para a Formação de Professores, Pareceres e Resoluções do Conselho Nacional de Educação.

O volume 1, no 1 , publicado em 2012, inaugura a publicação História Hoje sob nova estrutura a partir de dossiê temático "Ensino de História da África e da Cultura Afro-brasileira”, sob a coordenação da professora Martha Campos Abreu (UFF) e do professor Silvio de Almeida Carvalho Filho (UFRJ). O dossiê é composto por seis artigos: "Algumas impressões e sugestões sobre o ensino de História da África”, de Marina Mello e Souza (USP); "Entre máscaras e espelhos: reflexões sobre a Identidade e o ensino de História da África nas escolas brasileiras", de Anderson Ribeiro Oliva (UNB); "Os dilemas de dois autores frente a 'Uma história do negro no Brasil'”, de Wlamyra Albuquerque (UFBA) e Walter Fraga Filho (UFRB); "Proposta de material didático para a história das relações étnico-raciais", de Verena Alberti (CPDOC/UERJ); "O ensino de história entre o dever de memória e o direito à história", de Júnia Sales Pereira (UFMG) e Luciano Magela Roza (UFMG) e, finalmente, “'Por uma autêntica democracia racial!': os movimentos negros nas escolas e nos currículos de história”, de Amílcar Araújo Pereira (UFRJ).

O coordenador e a coordenadora ressaltam, na Apresentação, a intenção em publicar trabalhos que revelassem os limites e potencialidades de experiências de implantação das leis 10.639/2003 e 11.645/2008, aliando tais experiências a reflexões sobre o ensino da História da África e da Cultura Afro-brasileira:

Nosso objetivo foi reunir trabalhos que discutissem as conquistas resultantes da implantação da obrigatoriedade legal do estudo da História da África e do Negro no Brasil, assim como os limites, problemas e desafios com que se defrontam os profissionais de educação que assumem tão importante tarefa. Mas, em meio a muitas dificuldades enfrentadas pelos professores - dentre elas a insuficiência de formação teórica e prática, a oposição de familiares e setores sociais, a carência de recursos pedagógicos para aprofundamento da temática -, é evidente que a Lei 10.639/2003, modificada pela Lei 11.645/2008, vem sendo implantada e, hoje, podemos acompanhar diversas experiências positivas em várias unidades escolares espalhadas pelo Brasil. Sem dúvida, os visíveis esforços nesse sentido contribuem significativamente para a construção de uma sociedade brasileira mais justa e mais livre dos preconceitos e discriminações que sempre acompanharam as visões sobre o africano e seus descendentes na Diáspora. Nosso dossiê visa 
também oferecer aos leitores, especialmente aos educadores e aos interessados em geral, caminhos de trabalhos pedagógicos e reflexões teóricas no que diz respeito ao "Ensino da História da África e da Cultura Afro-brasileira". (ABREU e CARVALHO FILHO, 2012, p. 13)

A professora Martha Abreu (2021), na entrevista realizada, ressalta a potencialidade do contexto em que o dossiê foi organizado, elaborado e publicado, especialmente no tocante ao intenso debate sobre as cotas para ingresso nas universidades. Sobre esse tema, vale lembrar que iniciativas de adoção de um sistema de cotas e de ações afirmativas como as da Universidade do Estado do Rio de Janeiro (UERJ), em 2003, e as da Universidade de Brasília (UnB), em 2004, fruto de ações, reivindicações e movimentos sociais, acarretaram a institucionalização legal, através da lei no 12.711 , de 29 de agosto de 2012, que dispõe sobre o ingresso nas universidades federais e nas instituições federais de ensino técnico de nível médio. A professora menciona a polêmica, em 2010, sobre a constitucionalidade do sistema de cotas, especialmente do apoio de pesquisadores de várias universidades brasileiras ao posicionamento do historiador Luiz Felipe de Alencastro, que analisou como "obsoleta" a arguição de inconstitucionalidade impetrada no Supremo Tribunal Federal (STF) a respeito do sistema de cotas da Universidade de Brasília. Em seu discurso, como representante da Fundação Palmares no STF, publicado na Folha de S. Paulo, Alencastro afirma:

Não se trata aqui de uma lógica indenizatória, destinada a garantir direitos usurpados de uma comunidade específica -como foi o caso, em boa medida, nos julgamentos sobre as terras indígenas. Trata-se, sobretudo, de inscrever a discussão sobre as cotas no aperfeiçoamento da democracia. Nesse sentido, a arguição de inconstitucionalidade impetrada no Supremo Tribunal Federal [que analisa a constitucionalidade do sistema de cotas da Universidade de Brasília] revela-se obsoleta. Na verdade, as cotas raciais beneficiaram e beneficiam dezenas de milhares de estudantes nas universidades privadas no quadro do ProUni e 52 mil estudantes nas universidades públicas, funcionando há vários anos, com grande proveito para a comunidade acadêmica e para o país. (ALENCASTRO, 2010, s. p.)

A intenção de, com o dossiê, dar visibilidade às produções de intelectuais negros e de movimentos negros, de forma a expressar a intrínseca relação entre reflexões acadêmicas e os fazeres e saberes nas práticas pedagógicas na 
Educação Básica, parece ter encontrado eco e se concretizado. Inclusive, a experiência entre os diferentes níveis de ensino é ressaltada ao apresentar a professora Mônica Lima e Souza, entrevistada pelos organizadores do dossiê:

Mônica Lima possui uma longa experiência de ensino em História da África nos níveis fundamental, médio e universitário. Entre 1984 e 2010, atuou na rede pública estadual do Rio de Janeiro e no Colégio de Aplicação da UFRJ, onde também se dedicou à formação de professores de História. Atualmente é professora do Instituto de História da UFRJ e coordenadora do LEÁFRICA (Laboratório de Estudos Africanos). Além de atuar na formação de professores de História, Mônica Lima é referência na área de pesquisa e ensino de História da África, ministrando cursos e consultorias sobre a temática. (ABREU e CARVALHO FILHO, 2012, p. 131)

A professora Martha lembra que a reivindicação pelo ensino da História e cultura negra é antiga, como é perceptível pela fotografia de uma manifestação ocorrida na 33a Reunião Anual da Sociedade Brasileira para o Progresso da Ciência (SBPC), em julho de 1981, na Universidade Federal da Bahia (UFBA), em Salvador, Bahia, reproduzida na capa do livro Cultura negra: festas, carnavais e patrimônios negros, ${ }^{3}$ e que hoje, ao rememorar o processo de organização do dossiê, sente falta de uma abordagem do "pós-abolição".

Figura 7 - Professora Martha Abreu em entrevista online, 26 mar. 2021.

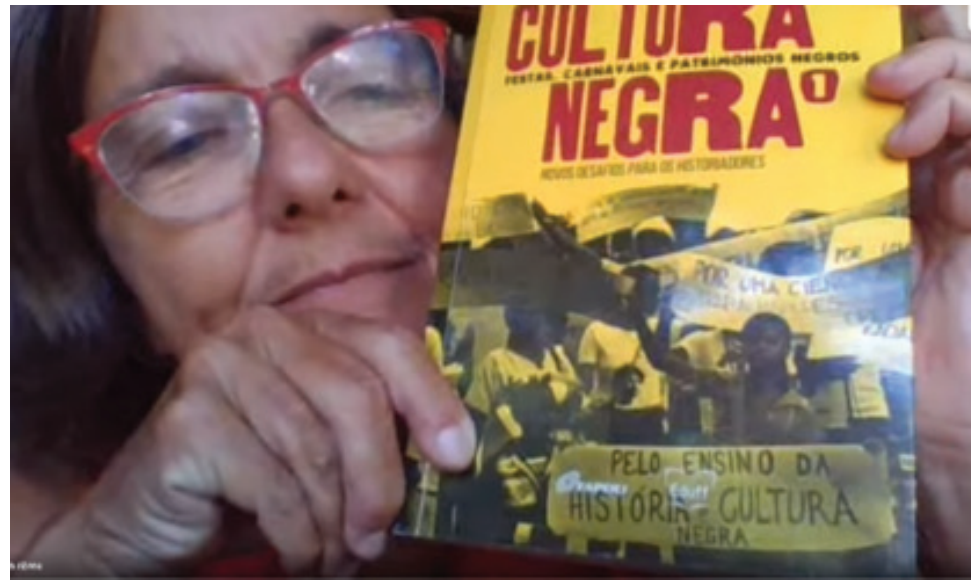

Fonte: Acervo da autora. 
Uma consulta ao currículo da professora Martha na Plataforma Lattes revela a presença constante, em sua trajetória acadêmica, de projetos de pesquisa relativos às questões cultura, identidade e diversidade no Brasil, com destaque para as alteridades afro-brasileiras. A mesma fonte revela a intensidade de estudos e pesquisas sobre a História da África realizados pelo professor Silvio de Almeida Carvalho Filho.

O número 1 da Revista História Hoje traz, também, um artigo em cada uma das seções Falando de História Hoje, E-Storia e História Hoje na Sala de Aula, duas resenhas e sete artigos. Tais artigos abordam, de certa forma, temáticas e questões relacionadas ao tema do dossiê. São eles: "Reflexões sobre o ensino colonial em África: trajetórias da instituição escolar no antigo Sudão (1889-1952)”, de Patrícia Teixeira Santos (UNIFESP); “As bandas de congo mirins: ensino popular e vivência de cultura afro-brasileira na Serra (ES)", de Michel Dal Col Costa (UFES); “Contribuições do Movimento Negro e das teorias críticas do currículo para a construção da educação das relações étnico-raciais", de Richard Christian Pinto Santos (UFMA) e Grace Kelly Silva Sobral Souza (UFMA); "Diásporas e comunidades quilombolas: perspectivas metodológicas para o ensino de história da África e da cultura afro-brasileira", de Maria Walburga Santos (UFSCar) e Ana Cristina Juvenal Cruz (UFSCar); “Para construir outro olhar: notas sobre o ensino de história e cultura africanas e afro-brasileiras", de Hilton Costa (UFPR); "Um olhar sobre a historiografia africana e afro-brasileira", de Luciano Everton Costa Telles (UEA) e "Espaço cibernético, cibercultura e pesquisa acadêmica”, de Marcos Silva (UFS).

Na seção Falando de História Hoje, que tem como intenção pautar questões da atualidade, Margarida Oliveira (UFRN) e Itamar Freitas (UFS) provocam reflexões a partir de dados de pesquisa sobre currículos de História em 18 estados brasileiros elaborados entre 2007 e 2012, tais como a necessidade de uma base comum ${ }^{4}$ em termos de expectativas de aprendizagem ao invés de termos um currículo pautado pelos sistemas nacionais de avaliação:

Após 25 anos de experiências curriculares, passando por dois grandes momentos na vida democrática - as lutas por extirpar os vestígios autoritários e as vitórias dos movimentos sociais -, não seria o momento de pensar numa base comum em termos de expectativas da aprendizagem ou, de maneira inversa, esperaremos que a disputa por cursos superiores (fundada na carência de vagas no setor 
público) transforme os itens de prova dos exames nacionais no currículo real para todos os brasileiros? (OLIVEIRA e FREITAS, 2012, p. 297)

Os autores Dilton Maynard (UFS) e Marcos Silva (UFS) afirmam que, coerente com a proposta da Revista História Hoje de ser "um suporte ao professor", a seção E-Storia tem como objetivo indicar sugestões sobre novas tecnologias aos navegantes, ultrapassando a mera listagem de endereços eletrônicos, sempre na perspectiva de compartilhar experiências e alternativas pedagógicas para o ensino de História.

A ideia aqui não é apresentar uma simples listagem de endereços eletrônicos, mas oferecer exemplos de ambientes que propiciem experiências pedagógicas inovadoras e que, em sua maioria, aliam um traço lúdico às atividades pedagógicas. Todavia, teremos sempre o cuidado de indicar diferentes caminhos possíveis. Poderemos apenas apontar um programa, aplicativo ou coisa do tipo, tendo o cuidado de explicar o seu potencial em sala de aula. Apresentaremos sítios resultantes de iniciativas isoladas, de professores ou memorialistas, páginas sem apoio financeiro e recursos sofisticados, mas também sítios eletrônicos construídos com amparo de órgãos de fomento e resultantes do empenho de equipes de profissionais, nem sempre todos eles da História. O ponto em comum será a capacidade que cada uma das experiências selecionadas terá de disponibilizar um olhar inovador no ensino de História. (MAYNARD e SILVA, 2012, p. 307)

A questão da relação entre as TICs e o ensino de História também é tema do texto "Detetives do passado no mundo do futuro: divulgação científica, ensino de História e internet", de Keila Grinberg (UNIRIO) e Anita Almeida (UFRJ), na seção História Hoje na Sala de Aula, ao apresentar o site Detetives do Passado, fruto de projeto desenvolvido em 2007. Segundo as autoras, o referido site "foi pensado como um espaço de atividades de investigação e pesquisa escolar, voltado para alunos da Educação Básica, tanto dos últimos anos do ensino fundamental, como do ensino médio" (GRINBERG e ALMEIDA, 2012, p. 320).

São duas as resenhas nesse primeiro número da Revista História Hoje, após a reestruturação de sua linha editorial: sobre Historiografia e Nação no Brasil, de Manoel Luiz Sagado, elaborada por Mauro Cézar Coelho (UFPA), e 
sobre Escritos sobre história e internet, de Dilton Maynard, elaborada por Anita Lucchesi.

"Ensino de História Indígena" é o tema do dossiê do volume 1, número 2, organizado pelas professoras Circe Maria Fernandes Bittencourt (PUC-SP) e Maria Aparecida Bergamaschi (UFRS), composto por cinco textos: "Os índios na história do Brasil no século XIX: da invisibilidade ao protagonismo", de Maria Regina Celestino Almeida (UFF); "Outra redução: a dinâmica interétnica na Limpia Concepción de Jeberos nas missões jesuíticas do Marañon no século XVII”, de Fernando Torres-Londoño (PUC-SP); “Categorias de entendimento do passado entre os Kadiwéu: narrativas, memórias e ensino de história indígena”, de Giovani José da Silva (UFMS); "Educação escolar indígena: a escola e os velhos no ensino da história Kaingang", de Juliana Schneider Medeiros (UFRGS) e "Da Escola Isolada Mista da Vila do Espírito Santo do Curipi à escola diferenciada entre os Karipuna: entrelaçamentos na história da educação escolar indígena”, de Edson Machado de Brito (IFBA).

As coordenadoras afirmam que a escolha da temática está relacionada com a obrigatoriedade do ensino de História e cultura afro-brasileira e indígena prescrita na lei 11.645 de 2008 visando "contribuir para a ampliação dos estudos sobre os povos indígenas e subsidiar as tarefas dos professores de História em suas aulas" (BITTENCOURT e BERGAMASCHI, 2012, p. 13).

Em entrevista, a professora Maria Aparecida Bergamaschi afirmou a intenção em explicitar as relações entre história, educação, conhecimentos e saberes indígenas. Nessa perspectiva, foi fundamental o dossiê conter texto de autores indígenas e de pesquisadores com atuação em escolas indígenas. Segundo a professora, havia uma preocupação com a formação docente, na medida em que poucos currículos de cursos de formação de História assumiram a inserção desse tema.

$\mathrm{Na}$ época sabíamos que era preciso produzir material para que os professores pudessem se apoiar. A Revista História Hoje cumpriu um papel importante, pois gerou um grande movimento ao abordar as temáticas das leis 10.639 de 2003 e 11.645 de 2008 nos dois primeiros números. Ainda não temos a escola sonhada em relação a isso. Professor leva muito do que lhe é mostrado na formação. E o currículo eurocentrado marca e acaba que os professores enfatizam a história da Europa. Muitos têm medo de inserir outros temas e não tratar da história já consagrada ou canonizada pela escola. (BERGAMASCHI, 2021) 
A professora Circe Bittencourt, ao ser entrevistada, reafirma tais intenções e apreensões, inclusive com a abordagem da educação indígena "antes do contato, após a chegada dos europeus e recente, após a lei 11.645” (BITTENCOURT, 2021). Lembra que, na época da organização do dossiê, vários indígenas eram estudantes no programa de pós-graduação da PUC-SP, alguns deles seus orientandos, o que facilitou o convite para a participação na edição. Ressalta a importância da Secretaria de Educação Continuada, Alfabetização, Diversidade e Inclusão (SECADI), ${ }^{5}$ no MEC, e, dessa maneira, contextualiza a entrevista realizada com Gersem José dos Santos Luciano - Gersem Baniwa, pela professora Maria Aparecida Bergamaschi.

Currículos escolares, história dos livros didáticos, história da educação, educação indígena e história dos ameríndios são alguns dos temas de inúmeros projetos de pesquisa desenvolvidos pela professora Circe Bittencourt. Ensino de história, educação ameríndia, interculturalidade, educação guarani, educação escolar indígena e a temática indígena na escola têm sido foco de estudos e pesquisas da professora Maria Aparecida Bergamaschi.

Além do dossiê, o volume 1, número 2 traz um texto em cada uma das seções Falando de História Hoje; E-Storia e História Hoje na Sala de Aula; duas Resenhas, "Os índios na história política do Império: avanços, resistências e tropeços", de Vânia Maria Losada Moreira (UFRRJ), e "Indígenas na história do Brasil: identidade e cultura", de Antônio Simplício de Almeida Neto (UNIFESP), além de quatro artigos: "Livro didático de História: representações do 'índio’ e contribuições para a alteridade”, de Maria de Fátima Barbosa da Silva (Secretaria Estadual de Educação do Rio de Janeiro); “A Educação Superior de Indígenas no Brasil contemporâneo: reflexões sobre as ações do Projeto Trilhas de Conhecimentos", de Antônio Carlos de Souza Lima (Museu Nacional Quinta da Boa Vista); “Histórias 'em suspenso': os Tembé 'de Santa Maria', estratégias de enfrentamento do etnocídio 'cordial”', de Jane Felipe Beltrão (UFPA) e "O ensino de História Indígena: possibilidades, exigências e desafios com base na Lei 11.645/2008”, de Edson Silva (UFPE). Com exceção dos textos "Espaço e tempo como dimensões do conhecimento e objeto de ensino-aprendizagem em História”, de Carlos Augusto Lima Ferreira (UEFS) e Edicarla dos Santos Marques (UEFS), da seção Falando de História Hoje, e o texto de Dilton Maynard (UFS) e Marcos Silva (UFS), da seção E-Storia, todos abordam questões relacionadas ao dossiê Ensino de História Indígena. 
O dossiê do volume 2, número 3, "O lugar da formação do professor nos cursos de História”, organizado pelas professoras Helenice Rocha (UERJ) e Wilma Baía Coelho (UFPA), é composto por sete textos: "Formação de professores: entre demandas e projetos", de Ana Maria Monteiro (UFRJ); “Professores em formação, formadores de professores: que profissão ensinam os cursos de graduação em História?”, de Aryana Lima Costa (UERN); “A didática da história e o desafio de ensinar e aprender na formação docente inicial”, de Cristiani Bereta Silva (UDESC) e Luciana Rossato (UDESC); "Professores iniciantes ensinando História: dilemas de aula e desafios da formação", de Flavia Eloisa Caimi (UPF); “Os dilemas da formação do professor de História no mundo contemporâneo”, de Helenice Ciampi (PUC/SP); "Desafios da formação inicial para a docência em História”, de Margarida Maria Dias Oliveira (UFRN) e Itamar Freitas (UFS), e "Formação de professores e ensino de História em limiares de memórias, saberes e sensibilidades”, de Sônia Regina Miranda (UFJF).

As organizadoras iniciam a apresentação do dossiê transformando o seu título em uma indagação: "Qual é o lugar da formação de professores de História no Brasil?” E, após apresentarem cada um dos textos, finalizam expressando o desejo que a diversidade de perspectivas possa instigar reflexões sobre "o fazer de todos nós, a formação em História":

Esperamos que os leitores usufruam da diversidade de perspectivas presente neste Dossiê. Especialmente aos estudantes de nossos cursos de História, professores do Ensino básico ou professores universitários formadores de professores, desejamos que esta leitura propicie novas reflexões acerca do fazer de todos nós, a formação em História, contribuindo para o estabelecimento de novas representações acerca dessa formação. (ROCHA e COELHO, 2013, p. 18)

A originalidade e ousadia na abordagem sobre o tema são pontos destacados pela professora Wilma Baía Coelho ao lembrar que, "até aquele momento, não havia nenhum dossiê sobre a formação de professores e ensino de História. Tratava-se, pois, de propiciar uma reflexão importante e oportuna pela dimensão política naquela ocasião" (COELHO, 2021). Oportuna devido ao intenso debate sobre as Diretrizes Curriculares Nacionais para a Formação de Professores da Educação Básica, em nível superior, curso de licenciatura, de graduação plena. Cabe lembrar que, ao longo da primeira década do século XXI, a 
elaboração das diretrizes curriculares dos cursos de licenciatura e a reformulação dos currículos desses cursos estavam presentes em fóruns, eventos e reuniões que discutiam os pressupostos e concepções norteadoras sobre a profissão docente presentes, por exemplo, na Resolução CNE/CP n ${ }^{\circ} 1$, de 18 de fevereiro de 2002; na Resolução CNE/CP n. ${ }^{\circ} 1$, de 17 de novembro de 2005 ou na Resolução CNE/CP no 1 , de 11 de fevereiro de $2009 .{ }^{6}$

A percepção da intrínseca relação entre a academia e a Educação Básica é outro destaque na fala da professora Wilma ao enfatizar que a temática formação do professor de História, presente em sua trajetória acadêmica desde o mestrado, projetos de pesquisas e orientações, articula o fato de "estar inserida numa faculdade de história sendo formadora de professores para atuação na Educação Básica”. Observa que ela e a professora Helenice Rocha buscaram autores que dado o vínculo com a pós-graduação ou órgãos como a CAPES, programas como o PNLD e/ou o PIBID, trariam relevante contribuição ao dossiê, devido à relação com a questão da formação. Uma possibilidade de questionar a "primazia acentuada da historiografia em detrimento ao ensino de História" nas publicações da Anpuh. E sentencia,

os cursos de formação precisam não só dialogar como aprender com a educação Básica. Isso precisa refletir nos no de GTs, publicações e Mesas nos eventos. É preciso compreender como a Escola Básica percebe o impacto da formação, não só a partir dos estagiários que recebe, mas dos colegas recém-formados. As questões/problemas da Educação Básica precisam ser transformados em objetos de pesquisa. É fundamental a equidade entre os associados. (COELHO, 2021)

Compõem o número 3, além do dossiê, a entrevista com Nilma Lino Gomes realizada por Wilma Baía Coelho e Patrícia Maria Melo Sampaio; o texto “O historiador entre o 'ofício' e a 'profissão': desafios contemporâneos”, de Benito Bisso Schmidt (UFRGS), na seção Falando de História Hoje; o texto "O passado em bytes: notas sobre os usos da internet nos livros didáticos de História”, de Dilton Maynard (UFS) e Marcos Silva (UFS), na seção E-Storia; “A análise de fontes e o modo de vida dos primeiros habitantes do nosso continente: pesquisa arqueológica na Educação Básica”, de Pamela Peregrino Cruz (Secretaria Estadual de Educação do Rio de Janeiro) e "Trabalhando com a história romana na Wikipédia: uma experiência em conhecimento colaborativo na universidade”, de Juliana Bastos Marques (UNIRIO), na seção História 
Hoje na Sala de Aula; a resenha de Silvana Rossélia Santos (UFAM) sobre o livro Cultura, escola tradição: mitoteca na escola baniwa, organizado por Maria Luiza Garnelo Pereira, Gabriel Arcanjo Santos Albuquerque, Sully Sampaio e Luís Carlos Brandão. A seção Resenhas traz também "Instruções aos colaboradores”, Editoria RHHJ - ANPUH/BR.

A seção artigos apresenta seis textos: "Desafios e experiências do ensino superior no interior do Brasil: a implantação do curso de História em Porto Nacional, Tocantins”, de Roniglese Pereira de Carvalho Tito (IBGE/SEDUC Tocantins); "Saberes indisciplinados: os conteúdos da história na escola e as aprendizagens para a vida”, de Sandra Regina Ferreira Oliveira (UEL); "Narrativa midiática e narrativa didática de história: caminhos entrecruzados na contemporaneidade", de Sônia Wanderley (UERJ); "Habilidades de Estudos Sociais para a professora primária: circulação e apropriação de representações em um projeto de aperfeiçoamento de professores”, de Aldaíres França (UFES) e Juçara Luzia Leite (UFES); "Da didática da História à história da História ensinada", de Kazumi Munakata (PUC/SP) e "Parece que você está invadindo um espaço que não é seu: professoras de História narram experiências do início de carreira”, de Elison Paim (UFSC).

\section{AUTORES E AUTORAS}

Quem são os autores e autoras dos três primeiros números da Revista História Hoje, após a sua reformulação? O caminho trilhado para tentar responder a essa pergunta buscou conhecer um pouco da atuação destes sujeitos por meio da identificação do vínculo institucional, área do conhecimento e nível de ensino, indicados na nota de rodapé de cada artigo. A Plataforma Lattes, uma das fontes pesquisadas para cotejar tais dados, revelou que, na maioria das vezes, houve uma mudança, especialmente no nível de ensino de atuação. Por exemplo, a maioria que à época da publicação era estudante de pós-graduação (mestrado ou doutorado) e exercia a docência na Educação Básica, atualmente, além de ter concluído seus estudos, é professor/a universitário/a.

Considerando os dados apresentados nas notas de rodapés dos artigos, em relação à totalidade de autores/as dos três números, é perceptível alguns dados majoritários em relação ao gênero, área de conhecimento, nível de en- 
sino e região: mulheres, História, universitário e Sudeste (com destaque para o Rio de Janeiro), respectivamente.

Figura 8 - Autoria: gênero, área de conhecimento e região.

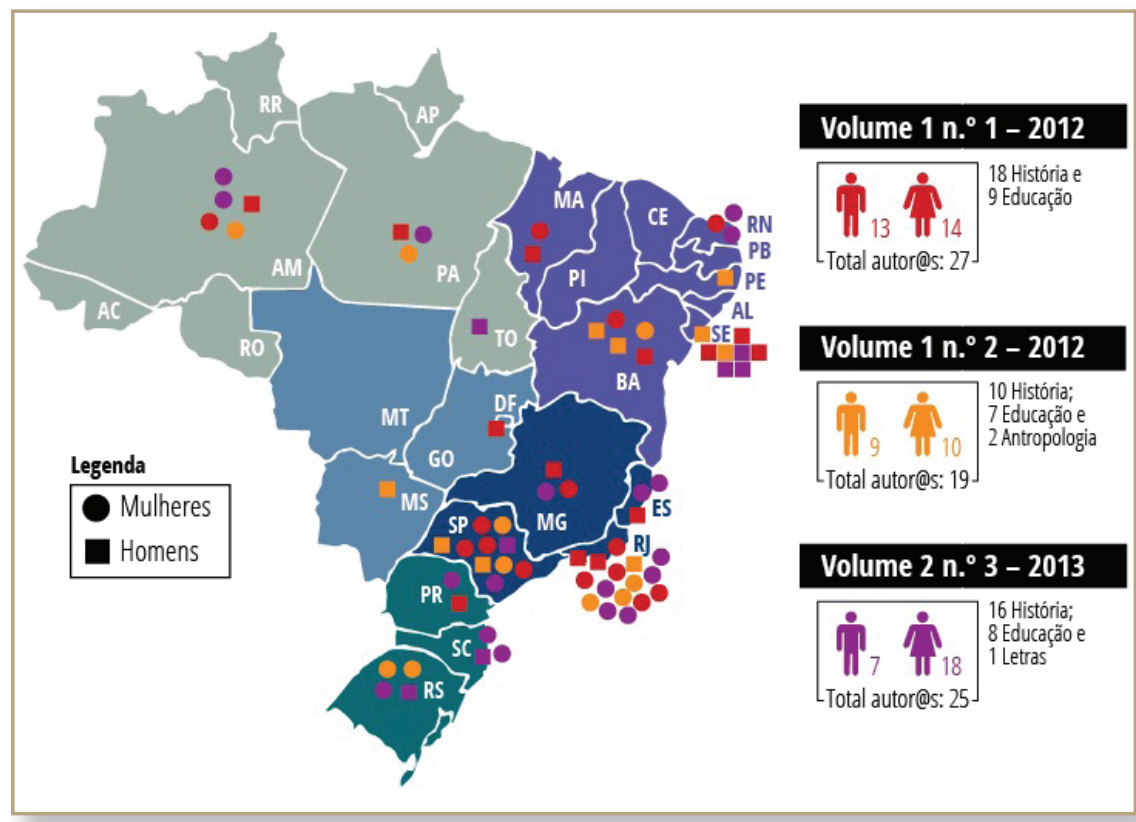

Fonte: Elaboração de Mohara Magalhães Villaça, mai. 2021.

Dos 27 autores e autoras as do volume 1, número 1, 20 são referenciados/ as como docentes universitários/as, sendo 15 em departamentos de História (sete homens e oito mulheres) e cinco em faculdades de Educação (três mulheres e dois homens); três doutorandos (dois homens e uma mulher); três mestrandos (dois homens e uma mulher) e uma graduanda em Pedagogia. 
Figura 9 - Área de atuação na docência universitária, RHHJ, v. 1, n. 1.

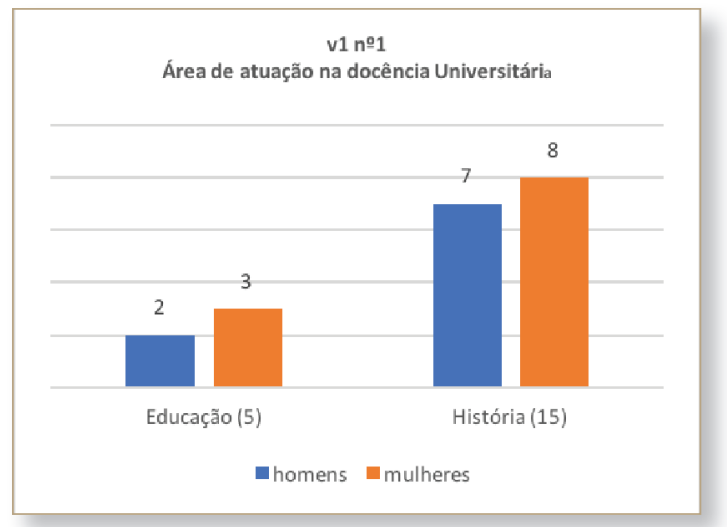

Fonte: Elaboração da autora.

Dos 19 autores do volume 1, número 2, 17 indicam docência exclusiva no nível universitário, sendo nove em departamentos de História (cinco homens e quatro mulheres), quatro em faculdades de Educação (três mulheres e um homem), dois em Antropologia (uma mulher e um homem); dois docentes universitários em concomitância (um com o doutorado e outro com exercício na Educação Básica); uma mestranda e uma professora da rede pública de ensino.

Figura 10 - Área de atuação na docência universitária, RHHJ, v. 1, n. 2.

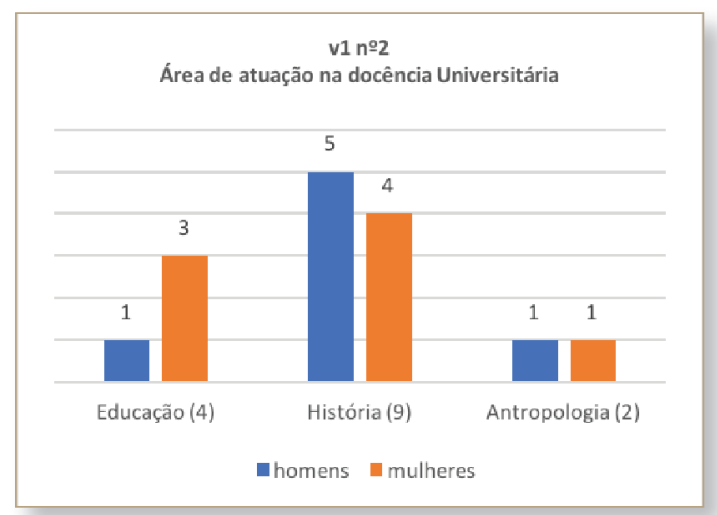

Fonte: Elaboração da autora. 
O volume 2, número 3, apesar da maioria ser docente universitário/a, é, entre as três publicações, a que conta com maior índice de autores com atuação na Educação Básica: cinco dos 25, sendo quatro mulheres e um homem. Dentre ele/as, somente uma atuava exclusivamente na Educação Básica, sendo da área de Letras. Os demais atuavam concomitantemente na docência ou como estudantes em cursos de pós-graduação ou, ainda, em instituições de pesquisa, como o Instituto Brasileiro de Geografia e Estatística (IBGE). Dos/as 20 autores/as com docência universitária exclusiva, 13 indicaram atuação em departamentos de História (dez mulheres e três homens) e sete em faculdades de Educação (quatro mulheres e três homens).

Figura 11 - Área de atuação na docência universitária, RHHJ, v. 1, n. 3.

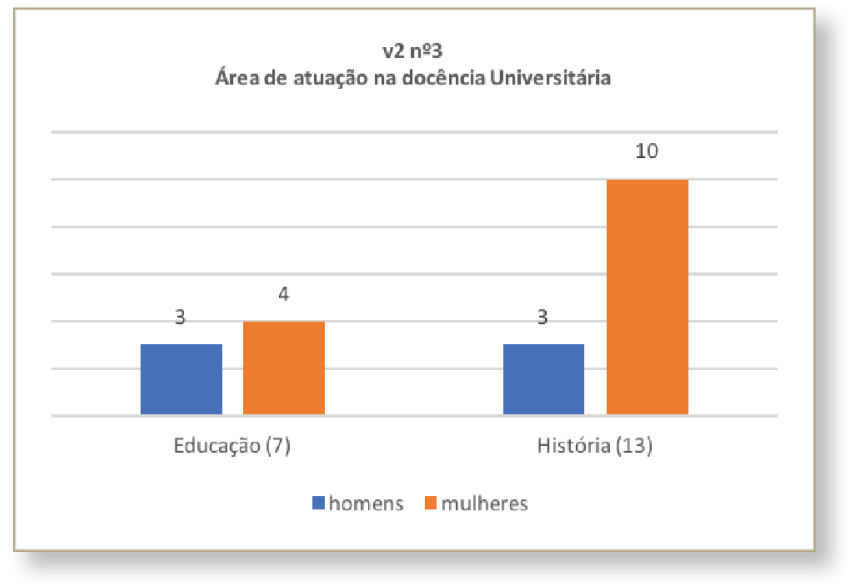

Fonte: Elaboração da autora.

\section{AVANÇOS E LIMITES; PERMANÊNCIAS E MUDANÇAS}

A análise do conjunto de textos dos três números da Revista História Hoje revela que a intenção em consolidar uma publicação de diálogo entre produções acadêmicas com questões da Educação Básica parece, em parte ter sido concretizada. Nesse sentido, é um passo importante para a Anpuh, como uma entidade que tem associados/as com atuação nos diferentes níveis de ensino.

Se por um lado é importante ressaltar a pertinência das temáticas "História da África e da Cultura Afro-brasileira”, "Ensino de História Indígena” e 
"Formação Docente" dos dossiês em relação a questões em pauta no contexto de cada publicação, por outro, alguns limites relativos ao nível de atuação e localização geográfica dos vínculos profissionais de autores e autoras, como a prevalência de docentes de universidades da Região Sudeste, também precisam ser apontados.

É imprescindível que a Revista História Hoje possa, realmente, romper com a hierarquização que persiste entre os níveis de ensino e entre as regiões de nosso país, propiciando um maior equilíbrio entre a "voz de professores/ as" da Educação Básica, docentes universitários e demais profissionais de História em atuação nas diversas instituições de ensino brasileiras.

\section{REFERÊNCIAS}

ABREU, Martha. Sobre o Dossiê "Ensino da História da África e da Cultura Afro-brasileira”. Entrevista concedida a Cláudia Sapag Ricci, 23/03/2021.

ABREU, Martha; CARVALHO FILHO, Sílvio. Apresentação - Dossiê. Revista História Hoje, v. 1, n. 1, 2012, p. 13-16.

ABREU, Martha; CARVALHO FILHO, Sílvio. Entrevista - Mônica Lima. Revista História Hoje, v. 1, n. 1, 2012, p. 131-136.

ALENCASTRO, Luiz Felipe de. Racismo e cotas. Pacto entre proprietários de escravos constitui o pecado original da sociedade e da ordem jurídica do Brasil. Folha de $S$. Paulo, Caderno Mais!. 07 de maio de 2010. Disponível em https://wwwl.folha.uol. com.br/fsp/mais/fs0703201009.htm. Acesso em: 04 mai. 2021.

ANPUH nacional. Atas de reuniões da diretoria nacional da ANPUH, 2009 a 2013.

APRESENTAÇÃO. Revista História Hoje, informações editoriais. Anpuh. Disponível em: https://anpuh.org.br/index.php/revista-historia-hoje/informacoes-editoriais-rhh/item/360-apresentacao. Acesso em: 20 mai. 2021.

BERGAMASCHI, Maria Aparecida. Sobre o Dossiê “Ensino de História Indígena”. Entrevista concedida a Cláudia Sapag Ricci, 26/03/2021.

BITTENCOURT, Circe. Sobre o Dossiê "Ensino de História Indígena”. Entrevista concedida a Cláudia Sapag Ricci, 31/03/2021.

BITTENCOURT, Circe Maria Fernandes; BERGAMASCHI, Maria Aparecida. Apresentação - Dossiê Ensino de História Indígena. Revista História Hoje, v. 1, n. 2, 2012, p. 13-19.

BRASIL. Ministério da Educação. Formação Superior para a Docência na Educação 
Básica. Disponível em: http://portal.mec.gov.br/pet/323-secretarias-112877938/ orgaos-vinculados-82187207/12861-formacao-superior-para-a-docencia-na-educacao-basica. Acesso em: 04 mai. 2021.

CENTRO DE FORMAÇÃO CONTINUADA DE PROFESSORES - FORPROF/UFRGS. Sobre a SECADI, s. d. Disponível em: https://www.ufrgs.br/renafor/about/sobre-a-secadi/. Acesso em: 20 mai. 2021.

CERRI, Luís Fernando. Sobre a reformulação editorial da Revista História Hoje. Entrevista concedida a Cláudia Sapag Ricci, 26/03/202.

COELHO, Wilma Baía. Sobre o Dossiê "O lugar da formação dos professores nos cursos de História”. Entrevista concedida a Cláudia Sapag Ricci, 24/03/2021.

DAHER, Julia. Especialistas avaliam fim de secretaria ligada à diversidade e inclusão. Carta Capital. 12 de abril de 2019. Disponível em: https://www.cartacapital.com. br/educacao/especialistas-avaliam-fim-de-secretaria-ligada-a-diversidade-e-inclusao/. Acesso em: 20 mai. 2021.

GRINBERG, Keila; ALMEIDA, Anita. Detetives do passado no mundo do futuro: divulgação científica, ensino de História e internet. Revista História Hoje, v. 1, n. 1, 2012, p. 315-326.

LEITE, Juçara Luzia. Sobre a editoria da Revista História Hoje. Entrevista concedida a Cláudia Sapag Ricci, 22/03/2021.

MAYNARD, Dilton; SILVA, Marcos. E-storia. Revista História Hoje, v. 1, n. 1, 2012, p. 249-252.

OLIVEIRA, Margarida; FREITAS, Itamar. Currículos de História e expectativas de aprendizagem para os anos finais do ensino fundamental no Brasil (2007-2012). Revista História Hoje, v. 1, n. 1, 2012, p. 269-304.

ROCHA, Helenice; COELHO, Wilma Baía. Apresentação - Dossiê "O lugar da formação do professor nos cursos de História”. Revista História Hoje, v. 2, n. 3, 2013, p. 15-18.

\section{NOTAS}

${ }^{1}$ Houve um retorno positivo por sete convidados/as e foi possível a realização de seis entrevistas via videochamada pelo Google Meet: Juçara Luzia Leite (22/03/2021); Martha Campos Abreu (23/03/2021); Wilma Baía Coelho (24/03/2021); Luís Fernando Cerri (26/03/2021); Maria Aparecida Bergamaschi (26/03/2021) e Circe Bittencourt (31/03/2021). Registro meus agradecimentos a todos/as que, gentilmente, compartilharam comigo suas memórias sobre $\mathrm{o}$ período em foco e participação na publicação da Revista História Hoje, assim como assumo inteiramente a responsabilidade pela transcriação de seus depoimentos. 
${ }^{2}$ Tal material - atas de 16 reuniões da diretoria nacional da Anpuh no período citado - foi gentilmente disponibilizado por Pablo Serrano, conforme orientação de Marcus Vinicius e solicitação do professor Renilson Ribeiro, a quem agradeço.

${ }^{3}$ O livro citado, organizado por Martha Abreu, Giovana Xavier, Lívia Monteiro e Eric Brasil, publicado pela editora da Universidade Federal Fluminense em 2018, pode ser baixado gratuitamente, no endereço: http://www.eduff.uff.br/ebooks/Cultura-negra-1.pdf.

${ }^{4}$ Importante ressaltar que este foi um dos textos indicados pela assessora, autora deste artigo, à equipe de especialistas do componente curricular História, no processo de elaboração da primeira versão da BNCC, em 2015, antes mesmo de convidar os dois autores para participar da referida equipe.

${ }^{5}$ Criada em julho de 2004, a SECADI/MEC era responsável pelos programas, ações e políticas de Educação Especial, Educação de Jovens e Adultos, Educação do Campo, Educação Escolar Indígena, Educação Escolar Quilombola, Educação para as relações Étnico-Raciais e Educação em Direitos Humanos. Foi extinta por meio do Decreto no 9.465, de 2 de janeiro de 2019, e criadas duas novas secretarias: a Secretaria de Alfabetização e a Secretaria de Modalidades Especializadas da Educação.

${ }^{6}$ No Portal do Ministério da Educação, item Formação Superior para a Docência na Educação Básica, há uma série de Pareceres e Resoluções do Conselho Nacional de Educação sobre o tema. Disponível em: http://portal.mec.gov.br/pet/323-secretarias-112877938/orgaos-vinculados-82187207/12861-formacao-superior-para-a-docencia-na-educacao-basica. Acesso em: 04 mai. 2021.

Artigo submetido em 31 de maio de 2021. 